Check for updates

Cite this: RSC Adv., 2021, 11, 10497

\title{
MoaGAA- $\mathrm{Fe}_{3} \mathrm{O}_{4} \mathrm{MNPs:}$ a highly efficient and environmentally friendly heterogeneous magnetic nanocatalyst for the synthesis of polyhydroquinoline derivatives
}

\author{
Mehraneh Aghaei-Hashjin, ${ }^{a}$ Asieh Yahyazadeh ${ }^{\star a}$ and Esmayeel Abbaspour- \\ Gilandeh (D)*b
}

Polyhydroquinolines were efficiently obtained from a sequential four-component reaction between dimedone or 1,3-cyclohexandione, ethyl acetoacetate, or methyl acetoacetate as a $\beta$-ketoester, aldehydes, and ammonium acetate, under the catalysis of Mo@GAA- $\mathrm{Fe}_{3} \mathrm{O}_{4}$ MNPs as a green, effective, recyclable, and environmentally friendly nanocatalyst. Due to its magnetic nature the prepared catalyst can be easily separated from the reaction mixture by an external magnet and reused several times without significant changes in catalytic activity and reaction efficiency. The catalyst was characterized using energy dispersive X-ray spectroscopy (EDX), X-ray diffraction (XRD), thermogravimetric analysis (TGA), Fourier transform infrared spectroscopy (FTIR), vibrating sample magnetometry (VSM), scanning electron microscopy (SEM), and transmission electron microscopy (TEM).

Received 16th January 2021

Accepted 3rd March 2021

DOI: $10.1039 / \mathrm{d} 1 \mathrm{ra00396h}$

rsc.li/rsc-advances
Nowadays, remarkable attention has been paid to the use of magnetic nanoparticles (MNPs), as a bridge between homogeneous and heterogeneous catalysts, by scientific and industrial researchers because of their potential importance in modern chemical research. ${ }^{10}$ Some excellent physical and chemical features of MNPs such as separation by an external magnet, superparamagnetism, high surface area, and strong adsorption ability $^{\mathbf{1 1}}$ have expanded their utilization in the removal of heavy metal ions in wastewater, ${ }^{12-14}$ catalysis, ${ }^{15}$ and drug delivery. ${ }^{\mathbf{1 6}}$ However, some of the MNPs features such as a tendency to oxidize and accumulate during reactions, high initial chemical activity, and high surface area to volume ratio will reduce their catalytic activity and magnetic nature during the reaction period. ${ }^{17,18}$ Thus, to overcome this drawback and increase their chemical stability for the special application, functionalization and modification of their surface with organic or inorganic supports are necessary.

Molybdenum as a d-block transition metal has various oxidation states from -I to +VI and it has a significant role in the life evolution. Despite the little amount of molybdenum on the earth's crust, it could be known as an oxotransferases for the active places and cofactors of several enzymes that catalyzes the oxygen and electron transfer reactions on the layers of nitrogen, carbon, and sulfur. ${ }^{19,20} \mathrm{Mo}(\mathrm{vI})$ is one of the main oxidation states that obtains a formal double bond between the metal and the oxo ligand via the donating $\sigma$ and $\pi$ bonds. There is a wide range of reports on the fabricated complexes using dioxomolybdenum(vi) obtained from varying the type and denticity of the remaining anionic ligands. ${ }^{\mathbf{2 1 - 2 4}}$ Among those, $\mathrm{MoO}_{2}(\mathrm{acac})_{2}$
${ }^{a}$ Chemistry Department, University of Guilan, Rasht 41335-1914, Iran

${ }^{b}$ Young Researchers and Elites Club, Ardabil Branch, Islamic Azad University, Ardabil, Iran.E-mail: abbaspour1365@yahoo.com 
is one of the most famous and major dioxomolybdenum(vi) complexes used as a catalyst for the organic transformations including epoxidation of alkenes and the oxidation of sulfides. ${ }^{25,26}$ Also, the coordination of molybdenum complexes by the organic groups (including oxygen, nitrogen, and sulfur) stabilized on the surfaces of magnetic nanoparticles has been used in many catalytic systems. ${ }^{27-30}$

Multicomponent reactions (MCRs), as a versatile synthetic strategy, combine at least three or more reactants ${ }^{31-34}$ via a single synthetic operation to generate several covalent bonds into structurally complex organic molecules containing most atoms of the available starting materials. ${ }^{35}$ Currently, MCRs are taken into consideration in the sustainable synthetic strategies, via which we can easily generate high compatibility with green chemistry due to their unique advantages, such as concomitant step economy, mild conditions, atom economy, and high convergence. Over the past decades and due to their various important applications in combinatorial chemistry, ${ }^{36}$ agrochemistry ${ }^{37}$ medicinal chemistry, ${ }^{38-40}$ polymer chemistry, ${ }^{31}$ and natural product synthesis, ${ }^{\mathbf{4 1}}$ MCRs have received considerable attention among organic chemists.

1,4-Dihydropyridine (1,4-DHP) core as an important class of nitrogen-containing heterocycles found in the nature have attracted considerable synthetic efforts over the past decade because of their diversity of biological functions, including antitubercular, ${ }^{42}$ neuroprotectant, ${ }^{43}$ antimicrobial, ${ }^{44}$ insecticidal, ${ }^{45}$ antiviral, ${ }^{\mathbf{4 6}}$ antihypertension, ${ }^{47}$ anticancer, ${ }^{48}$ and antioxidant $^{\mathbf{4 9 , 5 0}}$ activities. Amongst them, polyhydroquinoline derivatives are very interesting heterocyclic molecules due to their pharmacological properties such as anti-inflammatory, antimalarial, antibacterial, anti-asthmatic, and tyrosine kinase inhibiting agents. ${ }^{51-53}$ Many procedures have been developed for the preparation of polyhydroquinolines using catalysts such as ionic liquids, ${ }^{54}$ microwaves, ${ }^{55}$ refluxing at high temperature, ${ }^{56}$ metal triflates,${ }^{57}$ ceric ammonium nitrate (CAN) ${ }^{58}$ trimethylsilyl chloride (TMSCl), ${ }^{59}$ HY-zeolite $,{ }^{60} \mathrm{FeF}_{3},{ }^{61}$ silica perchloric acid $\left(\mathrm{HClO}_{4}-\mathrm{SiO}_{2}\right){ }^{62}$ trifluoroethanol, ${ }^{63}$ montmorillonite $\mathrm{K}-10,{ }^{64}$ iodine, ${ }^{65}$ autoclave, ${ }^{66} \mathrm{NiFe}_{2} \mathrm{O}_{4}$ MNPs, ${ }^{67}$ heteropoly acid, ${ }^{68} \mathrm{~L}^{-}$ proline $^{69}$ PTSA-SDS, $^{70} \mathrm{NiCuMgFe}_{2} \mathrm{O}_{4}$ MNPs, ${ }^{71}$ polymers, ${ }^{72}$ $\mathrm{Sc}(\mathrm{OTf})_{3},{ }^{73}\left\{\mathrm{Fe}_{3} \mathrm{O}_{4} @ \mathrm{SiO}_{2} @\left(\mathrm{CH}_{2}\right)_{3} \mathrm{Im}\right\} \mathrm{C}\left(\mathrm{NO}_{2}\right)_{3},{ }^{74} \mathrm{Yb}(\mathrm{OTf})_{3},{ }^{57} \mathrm{Fe}_{3^{-}}$ $\mathrm{O}_{4}$-adenine-Ni, ${ }^{75}$ BINOL-phosphoric acid derivatives, ${ }^{76}$ and $\mathrm{Cu}$ SPATB $/ \mathrm{Fe}_{3} \mathrm{O}_{4} \cdot{ }^{77}$ Although most of these procedures offer distinct merits, some of these procedures suffer from one or more limitations, such as generating a large amount of waste, low yields of the desired product, poor recovery of the catalyst, long reaction times, and hard reaction conditions. Therefore, to avoid these limitation based on the green chemistry protocols, the discovery of simple, efficient, versatile, and environmentally friendly processes for the synthesis of polyhydroquinolines is still favored.

\section{Experimental}

All of the chemical substances used in this work were purchased from Merck, Aldrich, and Fluka Chemical Companies and used without further purification. Melting points of the products were determined with an Electrothermal 9100 apparatus.
Energy-dispersive X-ray spectroscopy (EDX) was carried out on a FE-SEM (MIRA III, Detector of SAMX, France). Powder X-ray diffraction $(\mathrm{XRD})$ was performed using $\mathrm{Cu}-\mathrm{K} \alpha$ radiation $(\lambda=$ $1.54 \AA$ ) on a Philips-PW1730 in the $2 \theta$ range of $10^{\circ}-80^{\circ}$. Thermogravimetric analyses (TGA) were performed using a Linseis SATPT 100 thermoanalyzer at a heating rate of $10{ }^{\circ} \mathrm{C} \mathrm{min}^{-1}$ under nitrogen atmosphere over a temperature range of 25$700{ }^{\circ} \mathrm{C}$. The Fourier-transform infrared (FT-IR) spectra were recorded on a Perkin Elmer PXI spectrum, using pellets of the materials diluted with $\mathrm{KBr}$ in the range of $400-4000 \mathrm{~cm}^{-1}$. The magnetic features of the catalyst were determined using a vibrating sample magnetometer (VSM; MDK Co. Kashan, Iran) in the magnetic field range of -15000 Oe to 15000 Oe at room temperature. Scanning electron microscopy (SEM) images were recorded using an SEM-LEO 1430VP analyzer. Transmission electron microscopy (TEM) was utilized on a Zeiss-EM 900 instrument.

\subsection{Synthesis of $\mathrm{Fe}_{3} \mathrm{O}_{4}$ nanoparticles (MNPs)}

In the first step, a solution of $\mathrm{FeCl}_{2} \cdot 4 \mathrm{H}_{2} \mathrm{O}(0.86 \mathrm{~g})$ and $\mathrm{FeCl}_{3}$ $\cdot 6 \mathrm{H}_{2} \mathrm{O}(2.36 \mathrm{~g})$ were dissolved in deionized water $(40 \mathrm{~mL})$. The mixture was heated to $90{ }^{\circ} \mathrm{C}$, and mechanical stirring was done for 30 min under an argon atmosphere. Then, $10 \mathrm{~mL}$ of ammonia solution (25\%) was added dropwise to the resulting mixture and stirred for another 20 min under argon flow. The precipitates were washed with distilled water and collected using a magnet. The product was dried under vacuum conditions.

\subsection{Synthesis of $\mathrm{Fe}_{3} \mathrm{O}_{4} @ \mathrm{SiO}_{2}$ (SCMNPs)}

In a typical method, $1.0 \mathrm{~g}$ of obtained $\mathrm{Fe}_{3} \mathrm{O}_{4}$ nanoparticles was dispersed in a mixture of $60 \mathrm{~mL}$ ethanol, $20 \mathrm{~mL}$ deionized water, and $2 \mathrm{~mL}$ ammonia solution (25\%) by sonication for $10 \mathrm{~min}$. Then, $0.45 \mathrm{~mL}$ of tetraethylorthosilicate (TEOS) was added into the reaction system, sonicated for another $10 \mathrm{~min}$, and stirred at ambient temperature for $14 \mathrm{~h}$. The resultant precipitate was magnetically collected by a permanent magnetic field, washed three times with a mixture of ethanol and water $(1: 1)$, and dried in a vacuum oven.

\subsection{Functionalization of SCMNPs by 3 - aminopropyltriethoxysilane (Amp@SCMNPs)}

$1 \mathrm{~g}$ of core-shell $\mathrm{Fe}_{3} \mathrm{O}_{4} @ \mathrm{SiO}_{2}$ nanoparticles was suspended in $20 \mathrm{~mL}$ of dry toluene by ultrasonication. After treatment for $20 \mathrm{~min}, 2 \mathrm{~mL}$ of 3-aminopropyltriethoxysilane (Amp) was added to the solution and refluxed under an argon atmosphere. After $24 \mathrm{~h}$, the Amp@SCMNPs were collected using a permanent magnet, washed with ethanol and distilled water several times, and then dried under vacuum.

\subsection{Functionalization of Amp@SCMNPs by glutaraldehyde (imine@SCMNPs)}

$2 \mathrm{~g}$ of prepared Amp@SCMNPs nanoparticles was added to $100 \mathrm{~mL}$ ethanol and dispersed for $30 \mathrm{~min}$ under ultrasonic irradiation. Then, $4 \mathrm{mmol}$ of glutaraldehyde was added into the 
reaction solution and refluxed for $24 \mathrm{~h}$. The prepared solid product (imine@SCMNPs) was then magnetically isolated and washed several times with ethanol to remove unreacted glutaraldehyde; finally, it was dried under vacuum.

\subsection{Synthesis of GAA/imine@SCMNPs}

$1 \mathrm{~g}$ of the obtained imine@SCMNPs was dispersed in $25 \mathrm{~mL}$ DMF by the ultrasonic bath for $30 \mathrm{~min}$. Then, $0.85 \mathrm{mmol}$ of guanidineacetic acid (GAA) was added to the reaction solution. After the stirrer process for $8 \mathrm{~h}$, the resulting substance was separated by a permanent magnet, rinsed with ethanol several times, and dried under vacuum.

\subsection{Synthesis of Mo@GAA-Fe $\mathrm{F}_{3} \mathrm{O}_{4} \mathrm{MNPs}$}

$\mathrm{MoO}_{2}(\mathrm{acac})_{2}$ was prepared using the literature method. ${ }^{78} 2 \mathrm{~g}$ of GAA/imine@SCMNPs were added into $150 \mathrm{~mL}$ ethanol and a solution of $\mathrm{MoO}_{2}(\mathrm{acac})_{2}(4 \mathrm{mmol})$ in $70 \mathrm{~mL}$ ethanol was added to this reaction solution and refluxed for $12 \mathrm{~h}$. After magnetic separation, the resulting solid product was washed with dichloromethane to remove the unreacted $\mathrm{MoO}_{2}(\text { acac })_{2}$ and was dried under vacuum (Scheme 1).

\subsection{General procedure for the preparation of polyhydroquinolines}

Firstly, Mo@GAA- $\mathrm{Fe}_{3} \mathrm{O}_{4}$ MNPs $(10 \mathrm{mg})$ was poured into the reaction mixture of dimedone or 1,3-cyclohexandione (1 $\mathrm{mmol})$, ethyl acetoacetate, or methyl acetoacetate $(1 \mathrm{mmol})$, aldehydes $(1 \mathrm{mmol})$, and ammonium acetate $(1.2 \mathrm{mmol})$, and the reaction mixture was heated for a specific time. Upon completion of the reaction, the catalyst was easily extracted using an external magnetic field; the resulting product was collected by filtration, rinsed, and recrystallized with ethanol to give pure polyhydroquinolines.

\section{Results and discussion}

\subsection{FTIR analysis Mo@GAA-Fe $\mathrm{O}_{3} \mathrm{MNPs}$}

FTIR spectroscopy is one of the main techniques for the qualitative determination of the molecular structures in different species and the identification of existing functional groups in the structure. Fig. 1 shows FTIR spectra for SCMNPs, Amp@SCMNPs, imine@SCMNPs, GAA/imine@SCMNPs, and Mo@GAA- $\mathrm{Fe}_{3} \mathrm{O}_{4}$ MNPs. In the case of SCMNPs, the band at $585 \mathrm{~cm}^{-1}$, from the $\mathrm{Fe}-\mathrm{O}$ bond, verifies that the $\mathrm{Fe}_{3} \mathrm{O}_{4}$ lattice is formed. The presence of a broad peak at $3406 \mathrm{~cm}^{-1}$ is due to the $\mathrm{O}-\mathrm{H}$ stretching vibrations, which are attached to the $\mathrm{Fe}_{3} \mathrm{O}_{4}$

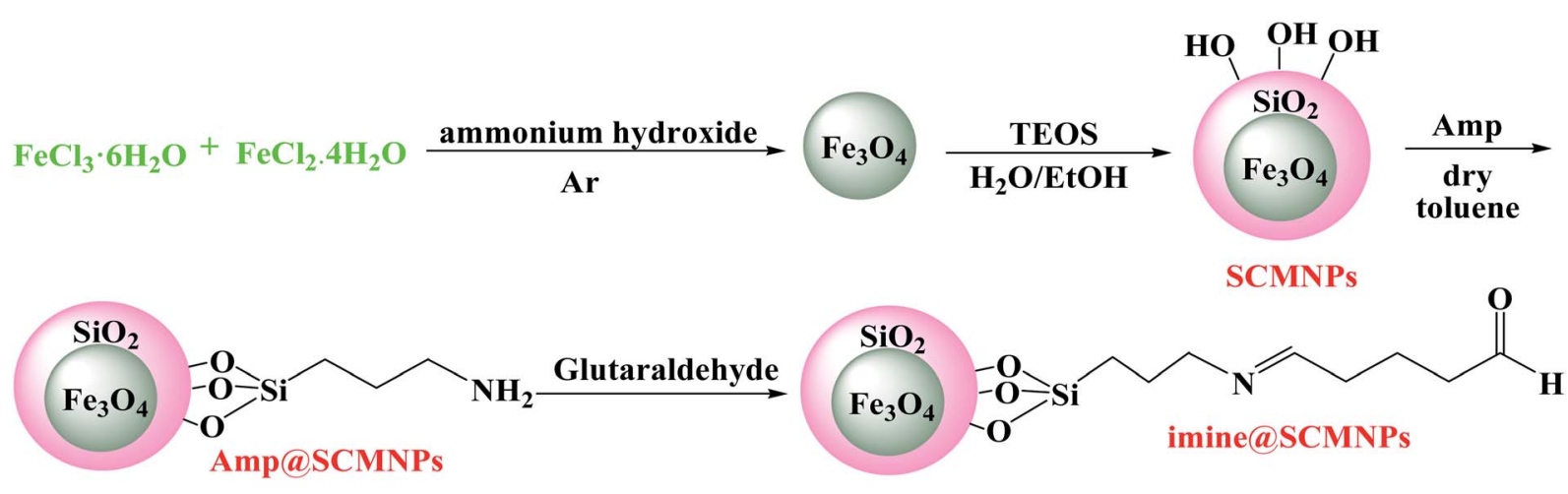

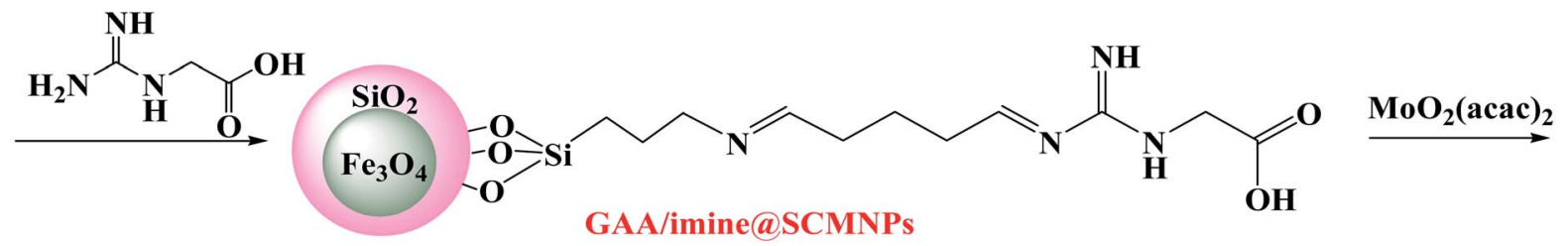

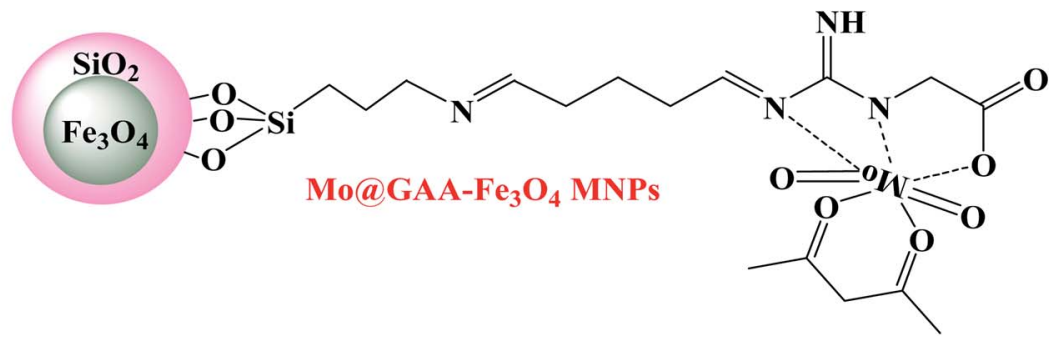




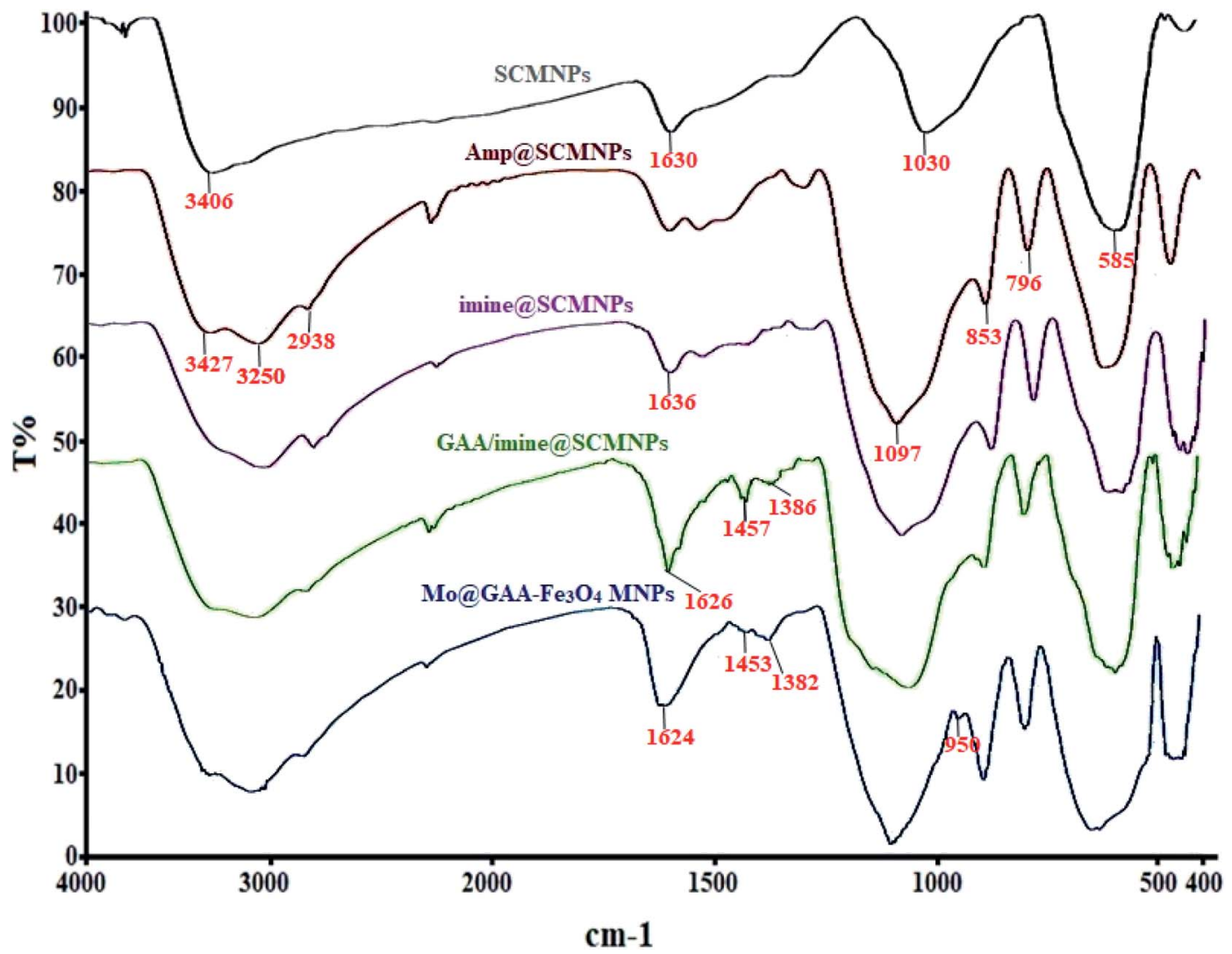

Fig. 1 FTIR spectra of SCMNPs, AmpasCMNPs, imine@SCMNPs, GAA/imine@SCMNPs, and Mo@GAA-Fe ${ }_{3} \mathrm{O}_{4} \mathrm{MNPs}$

surface. The above-mentioned structure has the symmetric stretching vibrations of $\mathrm{Si}-\mathrm{O}-\mathrm{Si}$ at around $1030 \mathrm{~cm}^{-1}$ and twisting bonds of $\mathrm{Si}-\mathrm{O}-\mathrm{H}$ and $\mathrm{H}-\mathrm{O}-\mathrm{H}$ at $1630 \mathrm{~cm}^{-1}$, indicating that the $\mathrm{Fe}_{3} \mathrm{O}_{4}$ nanoparticles (MNPs) contain silica layers. In the FT-IR spectrum of the Amp@SCMNPs can be observed the peaks for $\mathrm{C}-\mathrm{H}\left(2938 \mathrm{~cm}^{-1}\right)$, and $\mathrm{NH}_{2}\left(3250\right.$, and $\left.3427 \mathrm{~cm}^{-1}\right)$ stretching vibrations, which confirmed the successful covalent attachment of 3-aminopropyltriethoxysilane (Amp) to the SCMNPs surface. Also, vibrations at 796 and $853 \mathrm{~cm}^{-1}$ were probably attributed to the asymmetric stretching and in plane bending of $\mathrm{Si}-\mathrm{O}-\mathrm{Si}$ group, respectively. In about the imine@SCMNPs, the peak at $1636 \mathrm{~cm}^{-1}$ is assigned to the

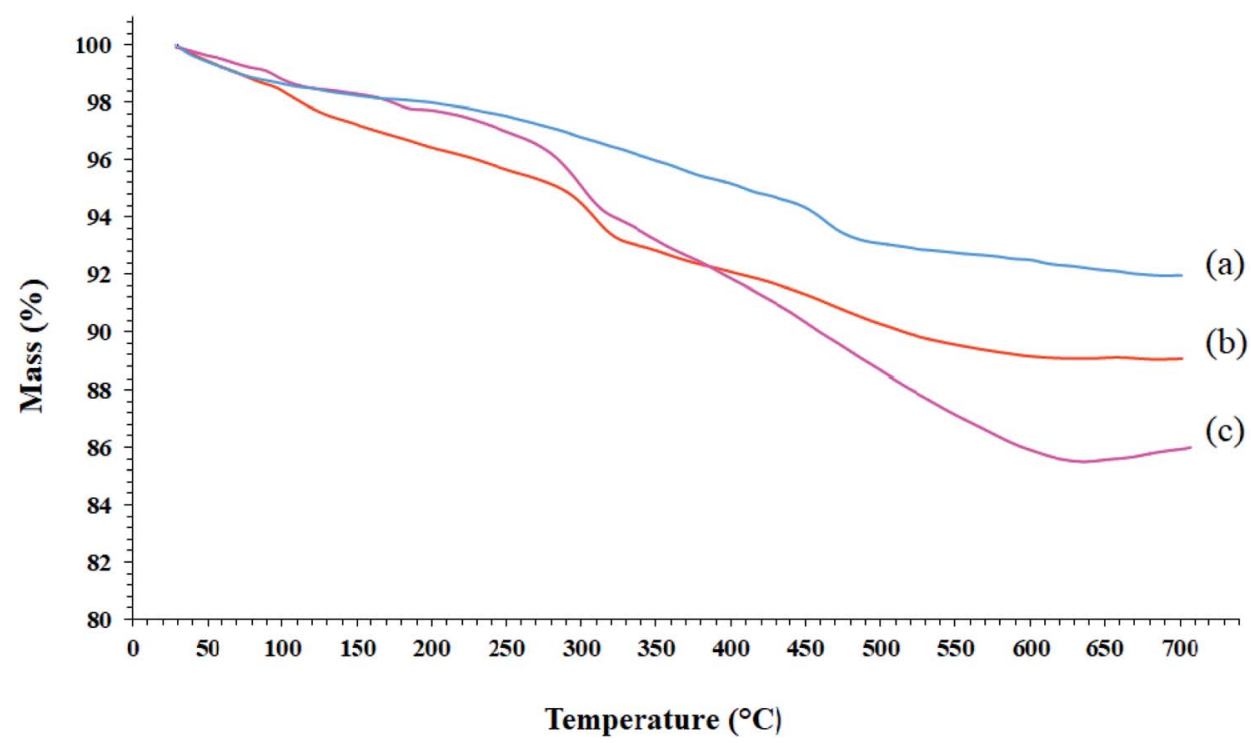

Fig. 2 TGA curves of (a) SCMNPs, (b) GAA/imineaSCMNPs, and (c) Mo@GAA- $\mathrm{Fe}_{3} \mathrm{O}_{4} \mathrm{MNPs}$. 


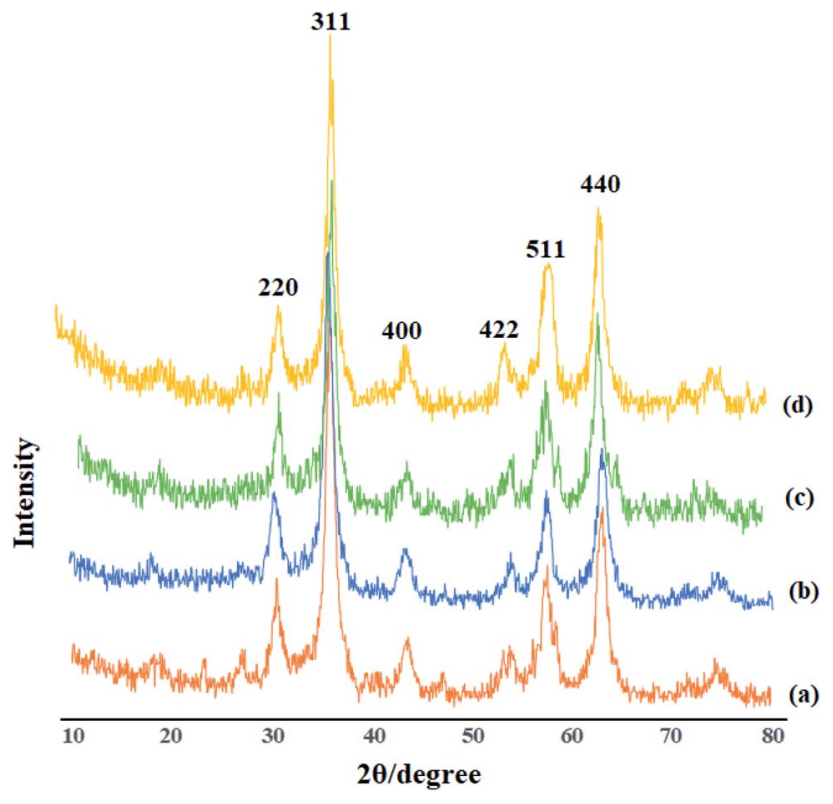

Fig. 3 XRD patterns of (a) $\mathrm{Fe}_{3} \mathrm{O}_{4}$, (b) GAA/imineasCMNPs, (c) Mo@GAA- $\mathrm{Fe}_{3} \mathrm{O}_{4}$ MNPs, and recovered Mo@GAA- $\mathrm{Fe}_{3} \mathrm{O}_{4}$ MNPs (d).

stretching vibrations of the $\mathrm{C}=\mathrm{N}$ bond, revealing the functionalization of the Amp@SCMNPs with glutaraldehyde groups. The bands at 1457 and $1626 \mathrm{~cm}^{-1}$ of the FTIR spectrum of GAA/ imine@SCMNPs can be assigned to the $\mathrm{C}-\mathrm{N}$ and $\mathrm{COO}$ stretching vibrations. Also, a broad band about $3000-3400 \mathrm{~cm}^{-1}$ can be ascribed to the acidic $\mathrm{OH}$ stretching vibrations. The peak observed at $950 \mathrm{~cm}^{-1}$ corresponds to the $\mathrm{MoO}_{2}$ group, which indicates the formation of the Mo@GAA- $\mathrm{Fe}_{3} \mathrm{O}_{4}$ MNPs. Moreover, the FTIR spectra of the catalyst show a frequency shift for some bonds, indicating the coordination of the metal with the desired bonds.

\subsection{TGA analysis of Mo@GAA- $\mathrm{Fe}_{3} \mathrm{O}_{4}$ MNPs}

TGA analysis can be used to determine the loading amount of the organic groups on the synthetic substrates. This measures the mass variations as a function of the temperature and time under a controlled atmosphere and indicates the thermal stability of the sample on a plot. The TGA analysis curves of SCMNPs, GAA/imine@SCMNPs, and Mo@GAA- $\mathrm{Fe}_{3} \mathrm{O}_{4}$ MNPs are shown in Fig. 2. All samples underwent a small weight loss below $200{ }^{\circ} \mathrm{C}$ due to water thermodesorption from the surface (drying). Another weight loss up to $700{ }^{\circ} \mathrm{C}$ was found in TGA curve of SCMNPs, which can be related to the release of hydroxyl ions from the nanoparticles and volatilization. In the TGA curves of GAA/imine@SCMNPs and Mo@GAA- $\mathrm{Fe}_{3} \mathrm{O}_{4}$ MNPs, another weight loss can be seen up to $650{ }^{\circ} \mathrm{C}$, which can be attributed to the decomposition of the functionalized organic groups.

\subsection{XRD analysis of Mo@GAA-Fe $\mathrm{O}_{3}$ MNPs}

Identification of the crystalline materials using X-ray is one of the most common and important analysis techniques. As the $\mathrm{X}$ ray region is located between gamma and ultraviolet, useful data could be obtained from this spectral region including the crystalline structure, the material type, and the nanoparticle size. The XRD patterns for $\mathrm{Fe}_{3} \mathrm{O}_{4}$ (a), GAA/imine@SCMNPs (b), Mo@GAA-Fe $\mathrm{O}_{4}$ MNPs (c) and recovered Mo@GAA-Fe $\mathrm{O}_{4}$ MNPs (d) are depicted in Fig. 3. The X-ray diffraction patterns of $\mathrm{Fe}_{3} \mathrm{O}_{4}$ magnetic nanoparticles display six diffraction peaks at $2 \theta=$ $30.5^{\circ}, 35.7^{\circ}, 43.8^{\circ}, 53.6^{\circ}, 57.5^{\circ}$, and $63.1^{\circ}$ (indexed as (220), (311), (400), (422), (511), and (440) reflection, associated with the crystalline structure of the spinel magnetic core). In addition, GAA/imine@SCMNPs and Mo@GAA- $\mathrm{Fe}_{3} \mathrm{O}_{4}$ MNPs have also similar diffraction peaks, indicating an unchanged

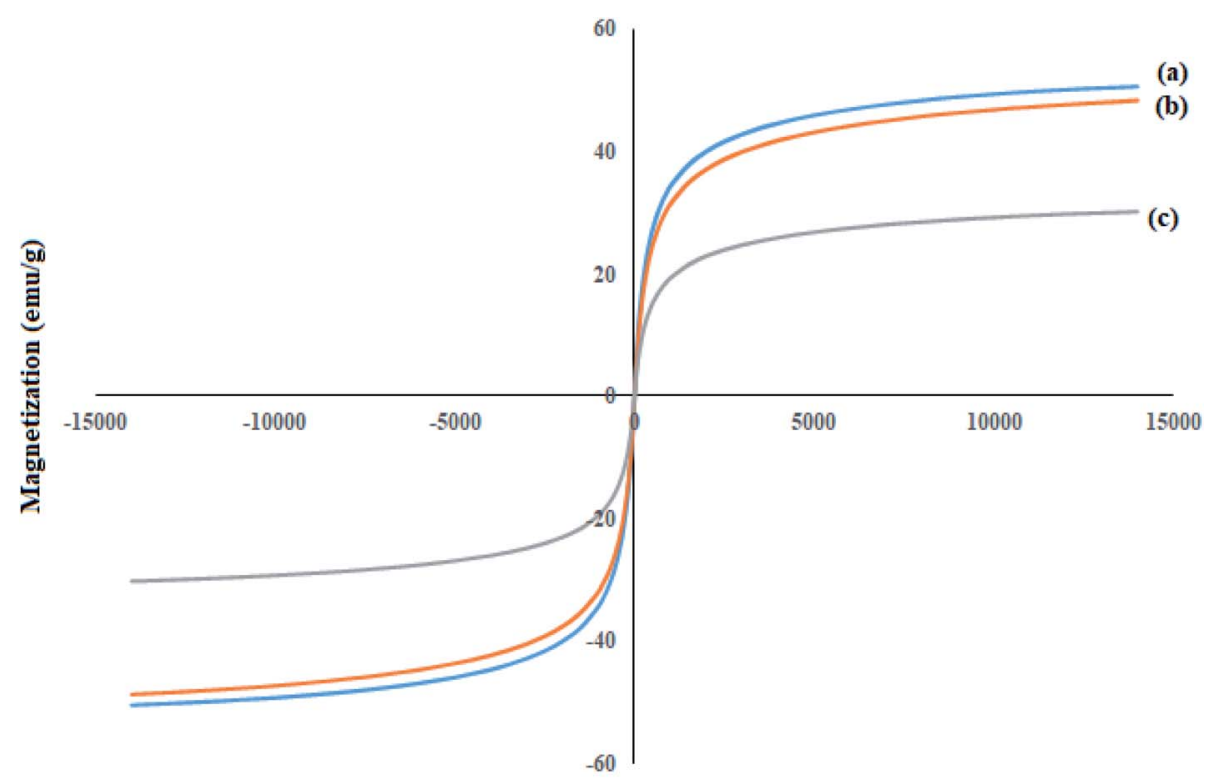

Applied Magnetic Field (Oe)

Fig. 4 VSM patterns of (a) $\mathrm{Fe}_{3} \mathrm{O}_{4}$, (b) SCMNPs, and (c) Mo@GAA- $\mathrm{Fe}_{3} \mathrm{O}_{4}$ MNPs. 
crystalline structure of the above-mentioned products. It is necessary to mention that the XRD pattern of recovered Mo@GAA- $\mathrm{Fe}_{3} \mathrm{O}_{4}$ MNPs after the first recovery and reuse do not show any change in crystalline structure.

\subsection{VSM analysis of Mo@GAA-Fe $\mathrm{O}_{3} \mathrm{O}_{4}$ MNPs}

Magnetic properties and the behavior of the achieved nanoparticles are investigated by the VSM analysis. An external magnetic field is applied to evaluate the magnetization ability of the magnetic nanoparticles. The VSM analysis of the synthesized (a) $\mathrm{Fe}_{3} \mathrm{O}_{4}$, (b) SCMNPs, and (c) Mo@GAA- $\mathrm{Fe}_{3} \mathrm{O}_{4}$ MNPs were shown in Fig. 4. The saturation magnetization values $\left(M_{\mathrm{s}}\right)$ of magnetic materials revealed significant differences, which are 50.63 and 47.16 emu g ${ }^{-1}$ for bare $\mathrm{Fe}_{3} \mathrm{O}_{4}$ and SCMNPs, respectively, while for catalyst, the difference is $28.99 \mathrm{emu}^{-1}$. As can be seen, the value of $M_{\mathrm{S}}$ for the catalyst decreased, which can be attributed to the functionalization of the $\mathrm{Fe}_{3} \mathrm{O}_{4}$ core by silica layers, organic molecules, and metal groups.

\subsection{SEM analysis of Mo@GAA- $\mathrm{Fe}_{3} \mathrm{O}_{4} \mathrm{MNPs}$}

The obtained images from the SEM technique could be used to study the morphology, uniformity, and physical properties of nanoparticle surfaces. High magnifications are obtained by this device to precisely investigate the material details. As shown in Fig. 5, $\mathrm{Fe}_{3} \mathrm{O}_{4}$ and SCMNPs are nearly spherical with a smooth surface and their mean particle sizes are 19 and $26 \mathrm{~nm}$, respectively. The obtained results clearly showed that the SCMNPs particles have grown compared to the $\mathrm{Fe}_{3} \mathrm{O}_{4}$. According to the represented images for GAA/imine@SCMNPs and Mo@GAA- $\mathrm{Fe}_{3} \mathrm{O}_{4} \mathrm{MNPs}$, the average size of the above-mentioned nanoparticles are in the range of 30-37 $\mathrm{nm}$. The modification by organic and metallic groups can result in the growth and accumulation of the nanoparticles.
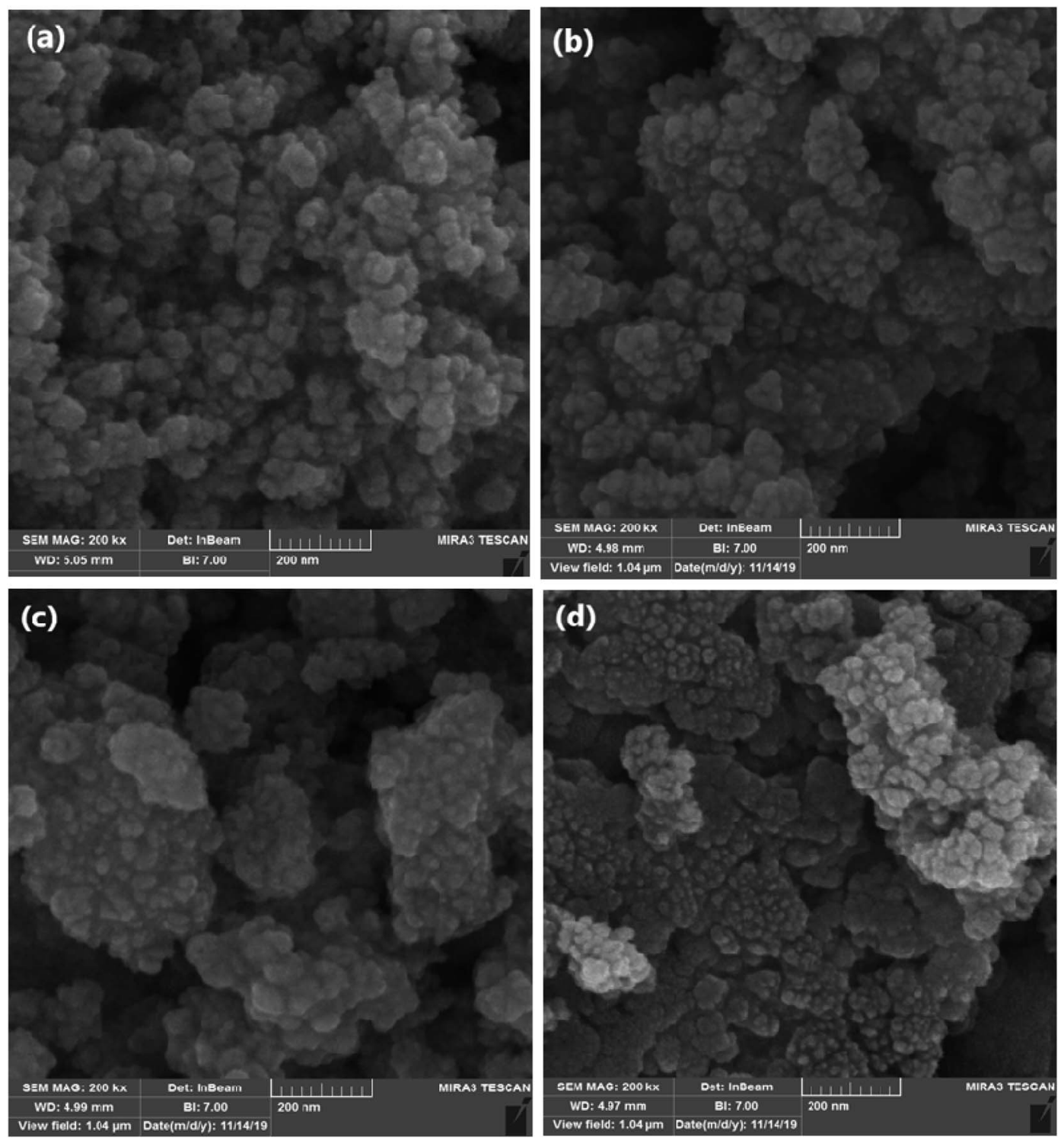

Fig. 5 SEM image of (a) $\mathrm{Fe}_{3} \mathrm{O}_{4}$, (b) SCMNPs, (c) GAA/imine (aSCMNPs, and (d) Mo(aGAA- $\mathrm{Fe}_{3} \mathrm{O}_{4}$ MNPs. 

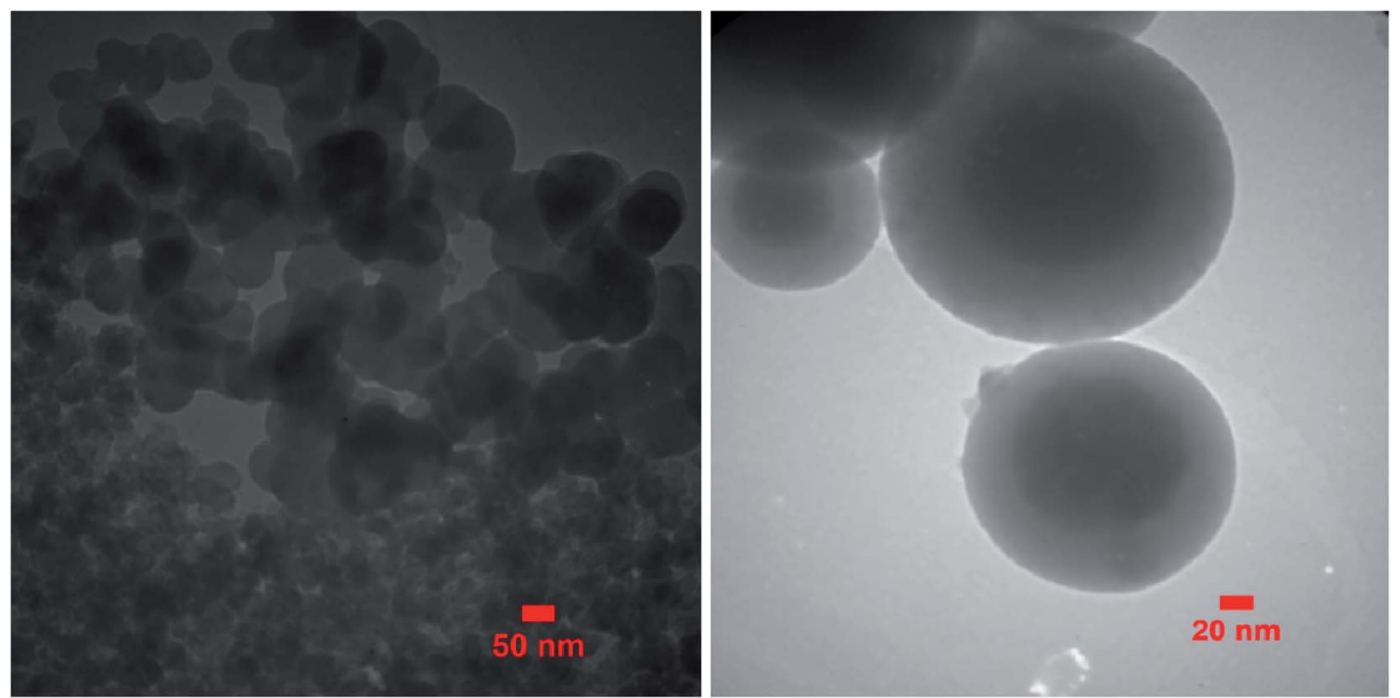

Fig. 6 TEM image of Mo(GAA- $\mathrm{Fe}_{3} \mathrm{O}_{4}$ MNPs.
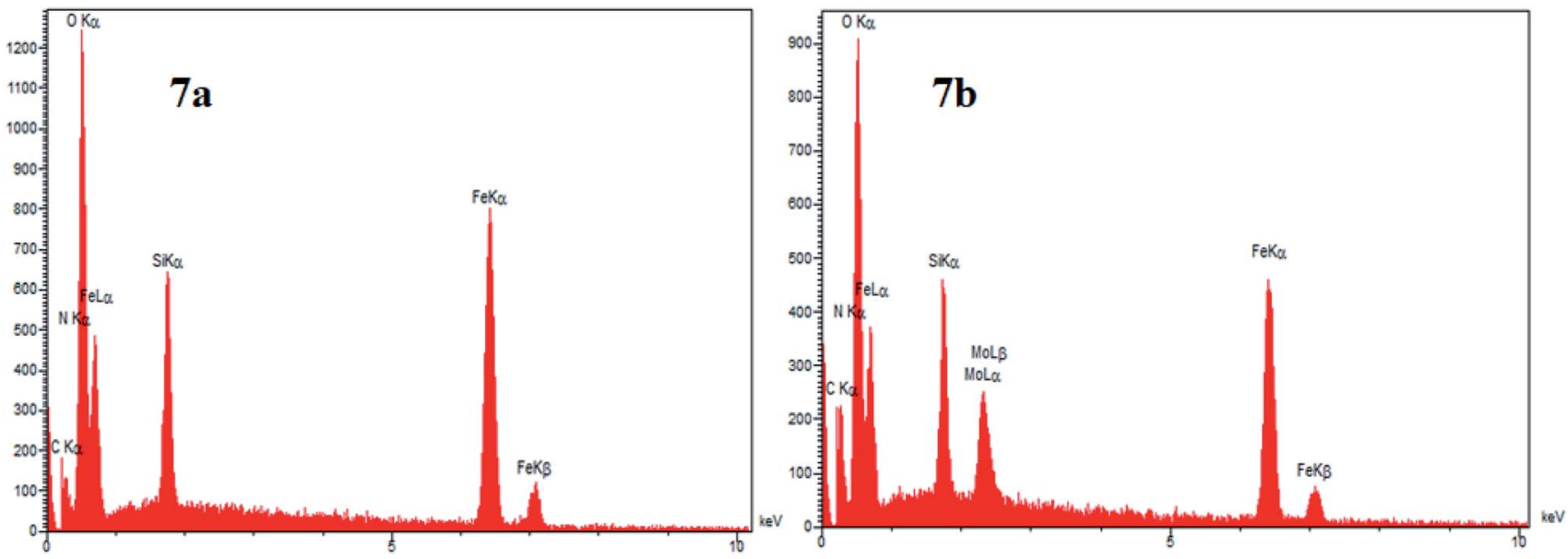

Fig. 7 EDX spectra of (a) GAA/imineaSCMNPs and (b) and Mo@GAA- $\mathrm{Fe}_{3} \mathrm{O}_{4} \mathrm{MNPs}$
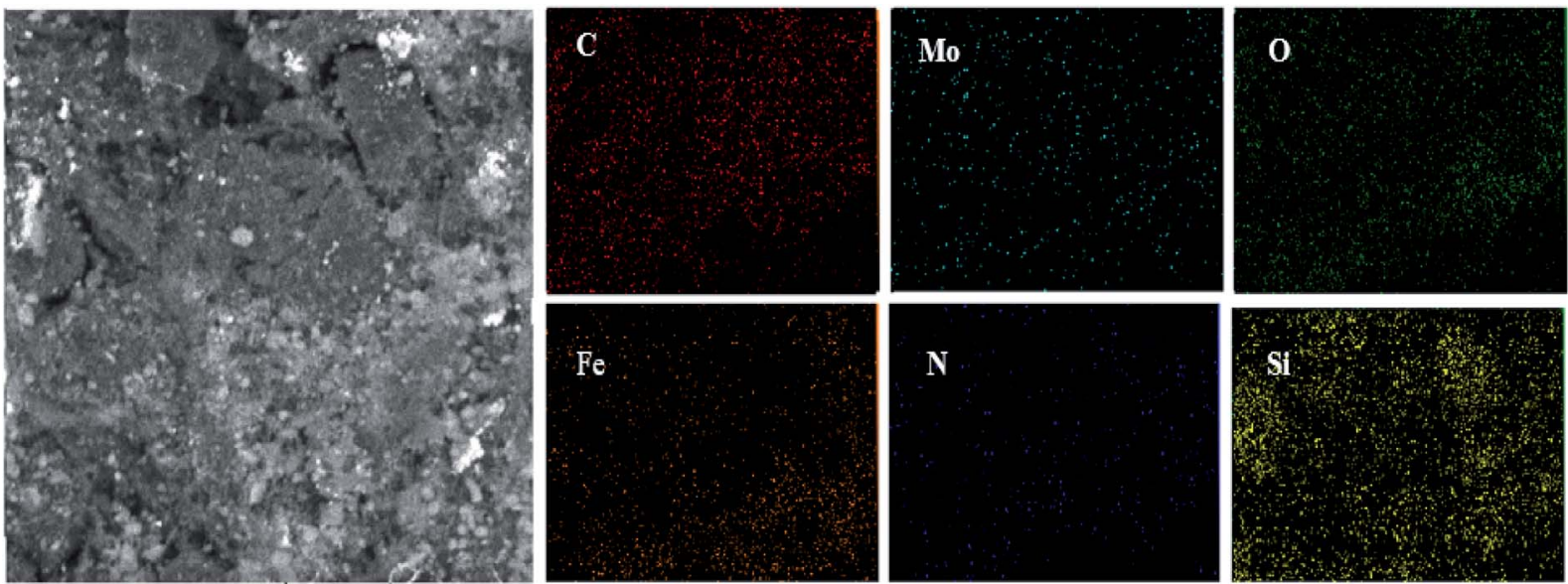

Fig. 8 SEM image of Mo@GAA- $\mathrm{Fe}_{3} \mathrm{O}_{4}$ MNPs nanocatalyst and corresponding quantitative EDX element mapping of $\mathrm{C}$, N, O, Fe, Si, and Mo. 


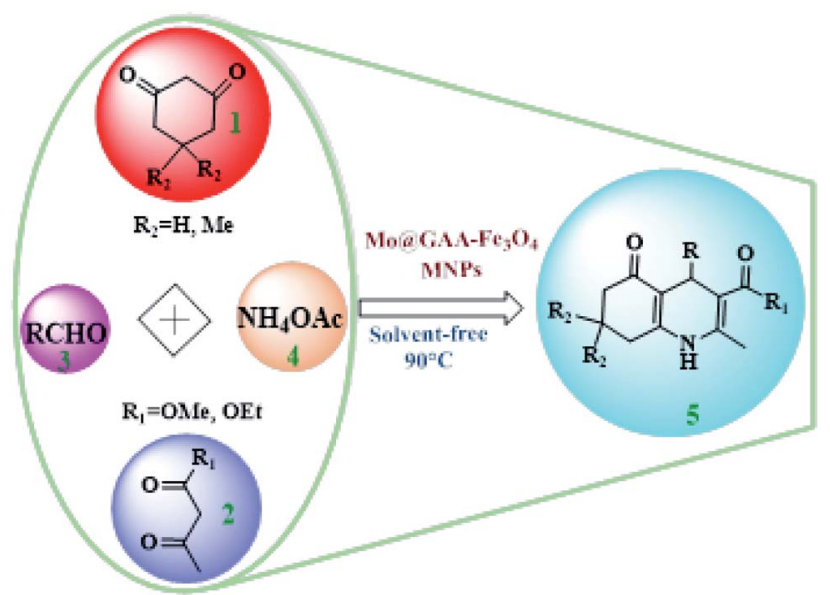

Scheme 2 Mo@GAA- $\mathrm{Fe}_{3} \mathrm{O}_{4}$ MNPs-catalyzed synthesis of polyhydroquinolines.

\subsection{TEM analysis of Mo@GAA- $\mathrm{Fe}_{3} \mathrm{O}_{4}$ MNPs}

In TEM analysis, a focused electron beam is used for obtaining the images. In this technique, some information from the inner structure could be obtained by transmitting a high-energy electron beam through a thin sample. Fig. 6 shows the TEM image of Mo@GAA- $\mathrm{Fe}_{3} \mathrm{O}_{4}$ MNPs. TEM images indicate that the diameter of the obtained catalyst is about $28-35 \mathrm{~nm}$ and it has a nearly spherical morphology with a narrow particle size distribution.

\subsection{EDX and elemental mapping analysis of Mo@GAA- $\mathrm{Fe}_{3} \mathrm{O}_{4} \mathrm{MNPs}$}

One of the main techniques to identify the elemental composition of the sample or a part of it is the EDX analysis. The EDX spectra of the GAA/imine@SCMNPs and Mo@GAA- $\mathrm{Fe}_{3} \mathrm{O}_{4} \mathrm{MNPs}$ is shown in Fig. 7a and b, respectively. In the case of GAA/ imine@SCMNPs, the presence of carbon, nitrogen, oxygen, iron, and silicon was confirmed (Fig. 7a). Also in Fig. 7b, the presence of the molybdenum element indicates coordination of Mo with nitrogen and oxygen electron pairs and thus the successful synthesis of the $\mathrm{Mo@GAA}-\mathrm{Fe}_{3} \mathrm{O}_{4} \mathrm{MNPs}$. In addition, Fig. 8 shows the elemental map of the Mo@GAA- $\mathrm{Fe}_{3} \mathrm{O}_{4} \mathrm{MNPs}$ nanocatalyst, which exhibits the presence of $\mathrm{C}, \mathrm{N}, \mathrm{O}, \mathrm{Fe}, \mathrm{Si}$, and Mo elements.

To synthesize new catalysts for certain organic processes, ${ }^{79-84}$ the synthesis of potentially active polyhydroquinoline derivatives (5) was investigated with various substituents from the reaction between dimedone or 1,3-cyclohexandione (1), ethyl acetoacetate, or methyl acetoacetate (2), aldehydes (3), and ammonium acetate (4) under solvent-free conditions using Mo@GAA- $\mathrm{Fe}_{3} \mathrm{O}_{4}$ MNPs as a novel, eco-friendly, reusable, and promising nanocatalyst (Scheme 2).

The catalytic activity of the Mo@GAA- $\mathrm{Fe}_{3} \mathrm{O}_{4}$ MNPs was surveyed in the preparation of polyhydroquinoline derivatives. Firstly, the condensation reaction of dimedone, ethyl acetoacetate, 4-chlorobenzaldehyde, and ammonium acetate in the presence of Mo@GAA- $\mathrm{Fe}_{3} \mathrm{O}_{4}$ MNPs was chosen as a model reaction. To optimize the reaction conditions, the synthesis of polyhydroquinolines we studied under various reaction conditions, including solvent, temperature, and the amount of catalyst. To optimize the reaction solvent, $\mathrm{H}_{2} \mathrm{O}$, EtOH, THF, $\mathrm{CH}_{2} \mathrm{Cl}_{2}$, $\mathrm{CH}_{3} \mathrm{CN}$, toluene, cyclohexane, and solvent-free conditions were tested (Entries 1-8). The results are summarized in Table 1, showing that carrying out the reaction in the absence of solvent led to the formation of the desired product $\mathbf{5 p}$ in the highest yield (Entry 8). However, a good yield of the product was

Table 1 Optimization one-pot four-component condensation of dimedone, ethyl acetoacetate, 4-chlorobenzaldehyde, and ammonium acetate, under different conditions ${ }^{a}$

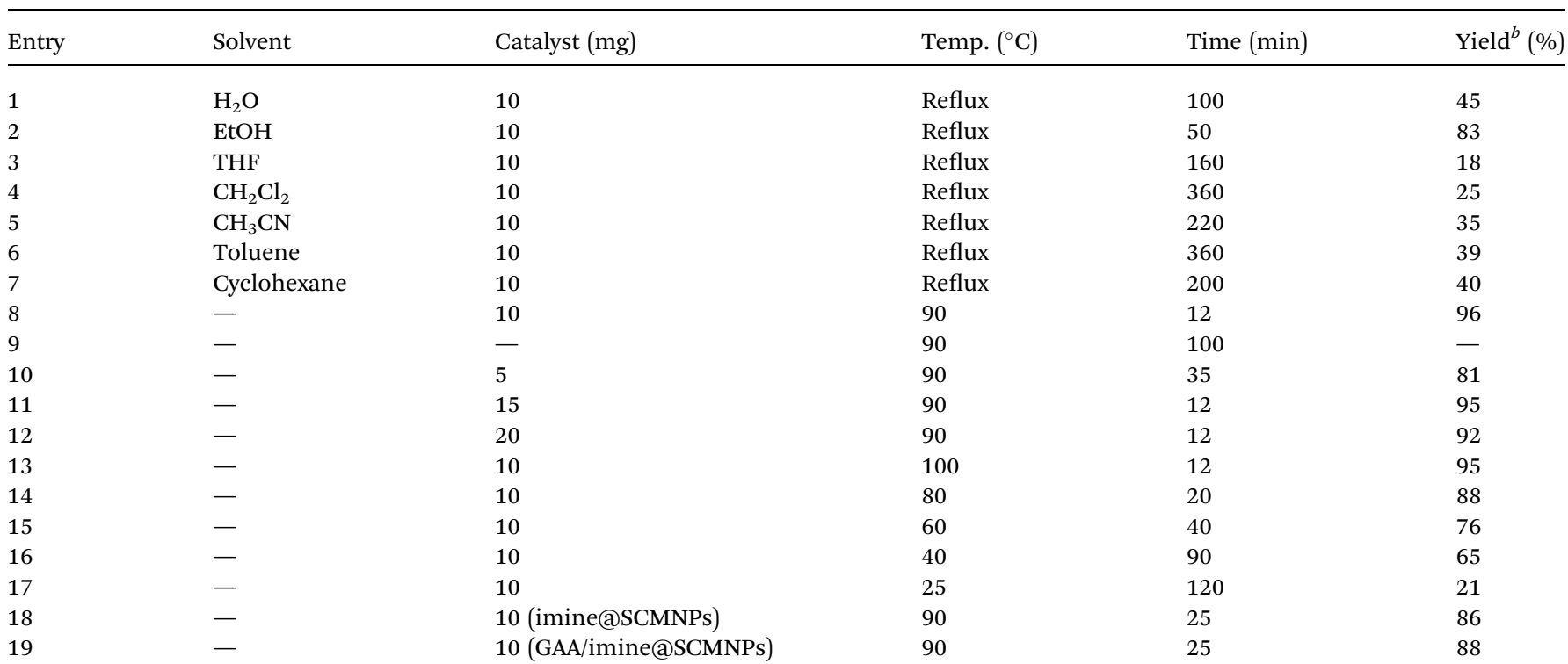

${ }^{a}$ Reaction conditions: dimedone $(1 \mathrm{mmol})$, ethyl acetoacetate $(1 \mathrm{mmol}), 4$-chlorobenzaldehyde $(1 \mathrm{mmol})$, and ammonium acetate $(1.2 \mathrm{mmol})$ and required amount of the catalyst. ${ }^{b}$ Isolated yield. 
Table 2 Preparation of polyhydroquinoline derivatives using desired catalyst ${ }^{a}$

Entry<smiles>O=Cc1ccc(Cl)cc1</smiles><smiles>O=Cc1ccc(O)cc1</smiles><smiles>COc1ccc(C=O)cc1</smiles>

3

4<smiles>Cc1ccc(C=O)cc1</smiles><smiles>O=Cc1ccccc1</smiles>

6<smiles>O=Cc1ccc(Cl)cc1</smiles>

$5 e$

$5 a$<smiles>COC(=O)C1=C(C)NC2=C(C(=O)CCC2)C1c1ccc(Cl)cc1</smiles>

5b<smiles>COC(=O)C1=C(C)NC2=C(C(=O)CCC2)C1c1ccc(O)cc1</smiles><smiles>COC(=O)C1=C(C)NC2=C(C(=O)CCC2)C1C(C)=O</smiles><smiles>COC(=O)C1=C(C)NC2=C(C(=O)CC(C)(C)C2)C1c1ccc(Cl)cc1</smiles>

$5 g$<smiles>COC(=O)C1=C(C)NC2=C(C(=O)CC(C)(C)C2)C1c1cccc([N+](=O)[O-])c1</smiles><smiles>Cc1ccc(C=O)cc1</smiles>

8

9<smiles>COc1ccc(C=O)cc1</smiles><smiles>COC(=O)C1=C(C)NC2=C(C(=O)CC(C)(C)C2)C1c1ccc(C)cc1</smiles>

15

95

256-258

20

93

269-272
13

93

222-224

93

253-256

15

20

92

208-211

208-211 (ref. 86)

17

13

15

20

221-223 (ref. 85)

256-257 (ref. 85)

238-240 (ref. 87)

236-238

257-259

257-259 (ref. 88)

219-221

220-222 (ref. 89)

90

223-225

222-223 (ref. 90)

270-274 (ref. 91)
256-259 (ref. 88)

$5 \mathbf{i}$ 
Table 2 (Contd.)

Entry RCHO

Product<smiles>O=Cc1ccccc1</smiles>

11<smiles>O=Cc1ccc(Cl)cc1</smiles>

12<smiles>O=Cc1ccc([N+](=O)[O-])cc1</smiles>

13<smiles>O=Cc1cccs1</smiles>

14<smiles>O=Cc1ccccc1</smiles>

15<smiles>O=Cc1ccccc1Cl</smiles>

16<smiles>O=Cc1ccc(Cl)cc1</smiles>

17<smiles>O=Cc1ccc(Cl)cc1Cl</smiles>

18<smiles>O=Cc1ccc([N+](=O)[O-])cc1</smiles>

5l

50

$5 p$

$5 q$
14

94

239-241

240-241 (ref. 91)

15

94

234-236

234-235 (ref. 91)

18

91

202-205

204-205 (ref. 91)<smiles>C=C1CCCC2=C1C(=C(C)OCC)C(C)=C(C)N2</smiles>

20

88

231-235

233-234 (ref. 91)

13

95

201-203

202-204 (ref. 57)<smiles>CCOC(=O)C1=C(C)NC2=C(C(=O)CC(C)(C)C2)C1c1ccccc1</smiles>

15

90

207-208

206-208 (ref. 92)<smiles>CCOC1=C(C)N(C)C2=C(CCCC2)C1CC</smiles><smiles>CCOC(=O)C1=C(C)NC2=C(C(=O)CC(C)(C)C2)C1c1ccc(Cl)cc1</smiles>

12

96

243-245

244-246 (ref. 93)

14

92

240-242

241-243 (ref. 57)<smiles>CCOC(=O)C1=C(C)NC2=C(C(=O)CC(C)(C)C2)C1c1ccc(Cl)cc1</smiles>

14

89

245-247

244-246 (ref. 92) 
Table 2 (Contd.)

\begin{tabular}{|c|c|c|c|c|c|c|}
\hline Entry & RCHO (3) & Product & Time (min) & Yield $^{b}(\%)$ & M.P. (Obsd) $\left({ }^{\circ} \mathrm{C}\right)$ & M.P. (Lit) $\left({ }^{\circ} \mathrm{C}\right)$ \\
\hline 19 & & & 15 & 91 & $218-221$ & $218-220$ (ref. 92) \\
\hline 20 & & & 20 & 92 & $210-213$ & 211-212 (ref. 72) \\
\hline 22 & & & 18 & 94 & $205-207$ & 204-206 (ref. 57) \\
\hline 25 & & & 45 & 72 & $148-150$ & 147-148 (ref. 57) \\
\hline
\end{tabular}

${ }^{a}$ Reaction conditions: dimedone or 1,3-cyclohexandione $(1 \mathrm{mmol})$, ethyl acetoacetate or methyl acetoacetate $(1 \mathrm{mmol})$, aldehydes $(1 \mathrm{mmol})$, ammonium acetate $(1.2 \mathrm{mmol})$ and catalyst $(10 \mathrm{mg})$ at $90{ }^{\circ} \mathrm{C} .{ }^{b}$ Isolated yields.

obtained in EtOH after 50 min from the start of the reaction (Entry 2). To study the role of catalyst amount, the model reaction was performed in the presence of 5, 10, 15, and $20 \mathrm{mg}$ of Mo@GAA- $\mathrm{Fe}_{3} \mathrm{O}_{4}$ MNPs (Entries 8 and 10-12). These observations showed that carrying out the reaction in the absence of the catalyst gave any yield for the desired product (Entry 9). The reaction in presence of $5 \mathrm{mg}$ of the catalyst provided a good yield of the product (Entry 10), while 10, 15, and $20 \mathrm{mg}$ gave excellent-to-high yields of the corresponding product (Entries 8 and 11-12). It was found that using $10 \mathrm{mg}$ of the Mo@GAA$\mathrm{Fe}_{3} \mathrm{O}_{4}$ MNPs is appropriate to carry out the reaction under solvent-free conditions with a $96 \%$ yield. Afterward, the influence of temperature on the model reaction was investigated. The reaction was carried out under different temperatures (25, $40,60,80,90$, and $100^{\circ} \mathrm{C}$ ) (Entries 8 and 13-17), and the best result was achieved at $90{ }^{\circ} \mathrm{C}$ under solvent-free conditions (Entry 8). Finally, when the model reaction was done in the existence of $10 \mathrm{mg}$ of imine@SCMNPs, GAA/imine@SCMNPs 
<smiles>[R]C=CO[Y4]([O-])([O-])c1ccccc1[N+](=O)[O-]</smiles><smiles>[R]C1=C(C)O[Y10]([CH])(CC(C)=O)O1</smiles><smiles>[R]C(=O)C=C(C)C(=O)CCC([R])=C1C(=O)CC([R2])([R2])CC1=O</smiles><smiles>[R]C(=O)C(C)C([R])C1=C(O)CC([R2])([R2])CC1=O</smiles>

B<smiles>[R]C(=O)C1=C(C)NC2=C(C(=O)CC([R])([R])C2)C1[R]</smiles><smiles>[R]C(=O)C(=C(C)N)C([R])C1=C(CC)CC([R2])([R2])CC1=O</smiles>

Scheme 3 Proposed mechanism for the synthesis of polyhydroquinoline derivatives.

under the optimized conditions, the product yield were 86 and $88 \%$, respectively (Entries 18-19). Comparing the product efficiencies for the inputs of 8 and 18-19, it could be fully understood that the coordination of the compound Mo@GAA- $\mathrm{Fe}_{3} \mathrm{O}_{4}$ MNPs by free electron pair of nitrogen with the molybdenum complex increased the catalytic activity.

Utilizing the optimal reaction conditions, various polyhydroquinolines were prepared by the four-component reaction of dimedone, or 1,3-cyclohexandione, ethyl acetoacetate or methyl acetoacetate, a wide range of aldehydes, and ammonium acetate (Table 2). Aromatic aldehydes with electron-donating or electron-withdrawing groups tolerate smooth transformation to the corresponding products without the formation of byproducts at better yields and in short reaction times. The reaction was also carried out with aliphatic aldehyde instead of aromatic aldehyde but did not afford the title products in considerable amounts (5y).

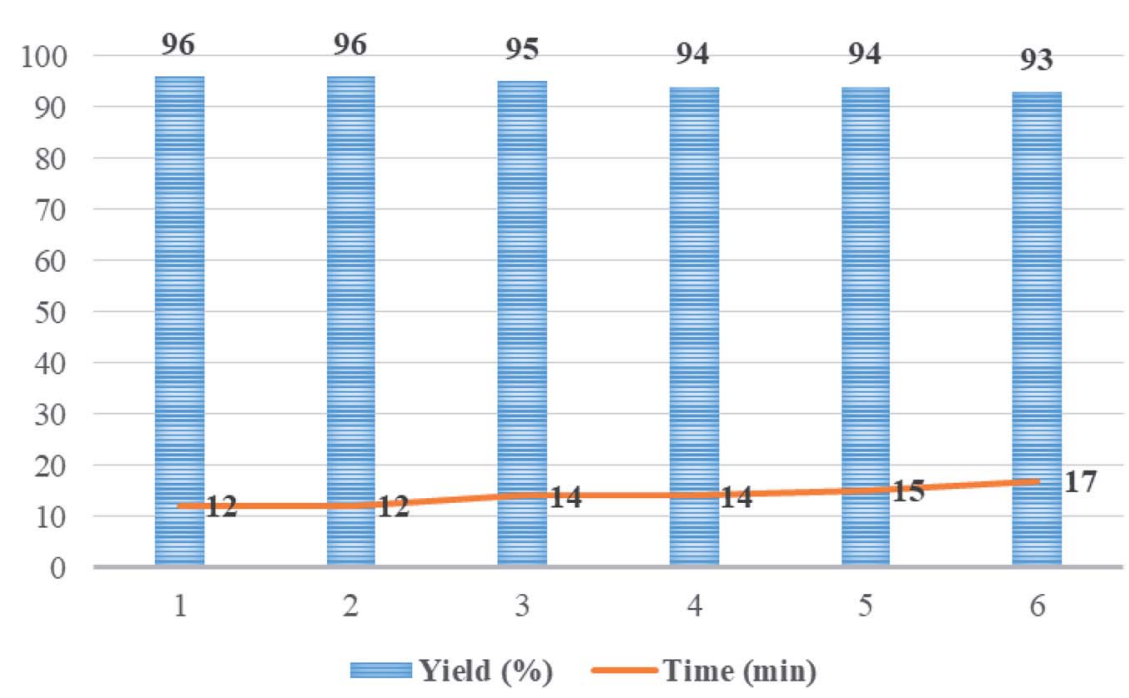

Fig. 9 The recycling of Mo@GAA- $\mathrm{Fe}_{3} \mathrm{O}_{4}$ MNPs as catalysts under solvent-free conditions in the synthesis of $5 p$. 
Table 3 Comparison of the results of the production of products $5 n$

\begin{tabular}{|c|c|c|c|c|c|}
\hline Entry & Catalyst and conditions & $\begin{array}{l}\text { Catalyst } \\
\text { loading }\end{array}$ & Time (h) & Yield (\%) & Ref. \\
\hline 1 & $\mathrm{Yb}(\mathrm{OTf})_{3} / \mathrm{EtOH} /$ r.t. & $5 \mathrm{~mol} \%$ & 5 & 90 & 57 \\
\hline 3 & $\mathrm{MgMnO}_{3} /$ solvent-free $/ 100{ }^{\circ} \mathrm{C}$ & $8 \mathrm{mg}$ & $33 \mathrm{~min}$ & 88 & 96 \\
\hline 4 & $\mathrm{FePO}_{4} / \mathrm{EtOH} /$ reflux & $2 \mathrm{~mol} \%$ & 1 & 96 & 97 \\
\hline 5 & $\mathrm{La}_{2} \mathrm{O}_{3} / \mathrm{TFE} /$ r.t. & $10 \mathrm{~mol} \%$ & 1 & 90 & 98 \\
\hline 8 & $\mathrm{Cu}(\mathrm{II})$-DCC-CMK-3/solvent-free $/ 80^{\circ} \mathrm{C}$ & $30 \mathrm{mg}$ & $30 \mathrm{~min}$ & 94 & 100 \\
\hline 9 & $\mathrm{Al}_{2}\left(\mathrm{SO}_{4}\right)_{3} / \mathrm{EtOH} /$ reflux & $10 \mathrm{~mol} \%$ & 4 & 92 & 101 \\
\hline 10 & Aluminized polyborate/solvent-free $/ 100{ }^{\circ} \mathrm{C}$ & $75 \mathrm{mg}$ & $20 \mathrm{~min}$ & 92 & 102 \\
\hline 11 & 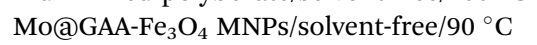 & $10 \mathrm{mg}$ & $13 \mathrm{~min}$ & 95 & This work \\
\hline
\end{tabular}

The plausible mechanism for the synthesis of polyhydroquinoline derivatives using Mo@GAA- $\mathrm{Fe}_{3} \mathrm{O}_{4}$ MNPs has been shown in Scheme 3. The metallic parts of the catalyst play a noticeable role in this organic transformation. Initially, Mo groups of the catalyst activate the $\mathrm{C}=\mathrm{O}$ functional groups of aldehyde and facilitate the condensation with dimedone or 1,3cyclohexandione and afford intermediate A. Then, Mo groups of the catalyst also activate $\mathrm{C}=\mathrm{O}$ functional groups of ethyl acetoacetate or methyl acetoacetate and increase the activity of this group. The condensation of ethyl acetoacetate or methyl acetoacetate and ammonium acetate resulted in intermediate $\mathbf{B}$. The Michael addition of intermediate $\mathbf{A}$ with intermediate $\mathbf{B}$ resulted in intermediate $\mathbf{C}$. The achieved compound is unstable and is converted to the resulting product in subsequent dehydration and cyclization.

After completion of the reaction as indicated by thin layer chromatography (TLC), the catalyst precipitate was easily filtered off from the product using an external magnetic field, washed with water/ethanol $(1: 1)$ to eliminate the residual product, dried under the vacuum oven, and reused under the same experimental conditions. The recycled catalyst was reused with a negligible reduction in catalytic activity and the product yield for six runs (Fig. 9). The yields of the product $5 \mathbf{p}$ for each of the six runs were $96,96,95,94,94$, and 93\%, respectively.

To show the merits of the Mo@GAA- $\mathrm{Fe}_{3} \mathrm{O}_{4}$ MNPs in comparison with previously reported catalysts in the literature for the synthesis of polyhydroquinoline derivatives, some of the results are tabulated in Table 3. As indicated in Table 3, the low catalyst loading of Mo@GAA- $\mathrm{Fe}_{3} \mathrm{O}_{4}$ MNPs can develop a suitable methodology in terms of the reaction times and yields, green chemistry, and compatibility with the environment.

\section{Conclusion}

In summary, the Mo@GAA- $\mathrm{Fe}_{3} \mathrm{O}_{4}$ MNPs were synthesized as an effective, recyclable, and environmentally friendly heterogeneous magnetic nanocatalyst that catalyzed the synthesis of biologically and pharmacologically interesting functionalized polyhydroquinoline derivatives under solvent-free conditions. The catalyst can be magnetically recovered from the reaction media by an external magnet and reused several times without any significant changes in the reaction efficiency. Moreover, high yields of products, short reaction times, lower loading of the catalyst, clean procedure, easy work-up, and heterogeneous reaction conditions are several advantages of this straightforward and efficient strategy.

\section{Conflicts of interest}

There are no conflicts to declare.

\section{References}

1 G. A. Somorjai and J. Y. Park, Angew. Chem., Int. Ed., 2008, 47, 9212.

2 Y. Liu, J. Zhang, X. Zhang, B. Li, X. Wang, H. Cao, D. Wei, Z. Zhou and A. K. Cheetham, J. Mater. Chem. A, 2016, 4, 4280.

3 G. Schmid, Nanoparticles: From Theory to Application, WileyVCH, Weinheim, 1st edn, 2004.

4 S. Duan, G. Han, Y. Su, X. Zhang, Y. Liu, X. Wu and B. Li, Langmuir, 2016, 32, 6272.

5 A. H. Lu, E. L. Salabas and F. Schuth, Angew. Chem., Int. Ed., 2007, 46, 1222.

6 C. Xing, Y. Liu, Y. Su, Y. Chen, S. Hao, X. Wu, X. Wang, H. Cao and B. Li, ACS Appl. Mater. Interfaces, 2016, 8, 15430.

7 K. Niknam and D. Saberi, Tetrahedron Lett., 2009, 50, 5210.

8 D. Astruc, F. Lu and J. R. Aranzaes, Angew. Chem., Int. Ed., 2005, 44, 7852 .

9 Y. Piao, Y. Jang, M. Shokouhimehr, I. S. Lee and T. Hyeon, Small, 2007, 3, 255.

10 M. Kidwai, A. Jain and S. Bhardwaj, Mol. Diversity, 2012, 16, 121.

11 X. F. Shen, Q. Wang, W. L. Chen and Y. H. Pang, Appl. Surf. Sci., 2014, 317, 1028.

12 D. P. Li, Y. R. Zhang, X. Zhao and B. X. Zhao, Chem. Eng. J., 2013, 232, 425.

13 Y. Y. Xu, M. Zhou, H. J. Geng, J. J. Hao, Q. Q. Ou, S. D. Qi, H. L. Chen and X. G. Chen, Appl. Surf. Sci., 2012, 258, 3897.

14 Y. R. Zhang, S. Q. Wang, S. L. Shen and B. X. Zhao, Chem. Eng. J., 2013, 233, 258. 
15 T. Zeng, W. W. Chen, C. M. Cirtiu, A. Moores, G. Song and C. J. Li, Green Chem., 2010, 12, 570.

16 M. Arruebo, R. Fernandez-Pacheco, M. R. Ibarra and J. Santamaria, J. Pharm. Sci., 2008, 97, 2948.

17 R. Y. Hong, B. Feng, G. Liu, S. Wang and H. Z. Li, J. Alloys Compd., 2009, 476, 612.

18 L. Vayssières, C. Chanéac, E. Tronc and J. P. Jolivet, J. Colloid Interface Sci., 1998, 205, 205.

19 S. Metz and W. Thiel, Coord. Chem. Rev., 2011, 255, 1085. 20 R. Hille, Dalton Trans., 2013, 42, 3029.

21 R. Sanz and M. R. Pedrosa, Curr. Org. Synth., 2009, 6, 239. 22 K. Jeyakumar and D. K. Chand, J. Chem. Sci., 2009, 121, 111. 23 R. Sanz and M. R. Pedrosa, Adv. Org. Synth., 2012, 4, 183.

24 D. K. Chand and R. D. Chakravarthy, Molybdenum Chloride Oxide, in Encyclopedia of Reagents for Organic Synthesis, Wiley, 2012.

25 I. Sheikhshoaie, A. Rezaeifard, N. Monadi and S. Kaafi, Polyhedron, 2009, 28, 733.

26 M. Bagherzadeh, M. M. Haghdoost and A. Ghanbarpour, Inorg. Chim. Acta, 2014, 411, 61.

27 M. Masteri-Farahani and N. Tayyebi,J. Mol. Catal. A: Chem., 2011, 348, 83.

28 M. Masteri-Farahani and Z. Kashef, J. Magn. Magn. Mater., 2012, 324, 1431.

29 N. Divsalar, N. Monadi and M. Tajbakhsh, J. Nanostruct., 2016, 6, 312.

30 N. Sadri, M. Moghadam and A. Abbasi, J. Mater. Sci.: Mater. Electron., 2018, 29, 11991.

31 R. Kakuchi, Angew. Chem., Int. Ed., 2014, 53, 46.

32 A. Domling and I. Ugi, Angew. Chem., Int. Ed., 1993, 32, 563.

33 O. Kreye, T. Toth and M. A. R. Meier, J. Am. Chem. Soc., 2011, 133, 1790.

34 I. Bae, H. Han and S. Chang, J. Am. Chem. Soc., 2005, 127, 2038.

35 J. Zhu and H. Bienaymé, Multicomponent Reactions, WileyVCH, Weinheim, 2005.

36 W. H. Moos, C. R. Hurt and G. A. Morales, Mol. Diversity, 2009, 13, 241.

37 C. Lamberth, A. Jeanguenat, F. Cederbaum, A. De Mesmaeker, M. Zeller, H. J. Kempf and R. Zeun, Bioorg. Med. Chem., 2008, 16, 1531.

38 I. V. Magedov and A. Kornienko, Chem. Heterocycl. Compd., 2012, 48, 33.

39 I. Akritopoulou-Zanze, Curr. Opin. Chem. Biol., 2008, 12, 324.

40 A. Dömling, W. Wang and K. Wang, Chem. Rev., 2012, 112, 3083.

41 B. B. Touré and D. G. Hall, Chem. Rev., 2009, 109, 4439.

42 A. Trivedi, D. Dodiya, B. Dholariya, V. Kataria, V. Bhuva and V. Shah, Chem. Biol. Drug Des., 2011, 78, 881.

43 V. Klusa, Drugs Future, 1995, 20, 135.

44 Y. L. N. Murthy, A. Rajack, M. Taraka-Ramji, J. Jeson-Babu, C. Praveen and K. Aruna-Lakshmi, Bioorg. Med. Chem. Lett., 2012, 22, 6016.

45 C. Sun, Y. Chen, T. Liu, Y. Wu, T. Fang, J. Wang and J. Xing, Chin. J. Chem., 2012, 30, 1415.

46 A. Hilgeroth, Mini-Rev. Med. Chem., 2002, 2, 235.
47 D. J. Triggle, D. D. Langs and R. A. Janis, Med. Res. Rev., 1989, 9, 123.

48 M. Kawase, A. Shah, H. Gaveriya, N. Motohashi, H. Sakagami, A. Varga and J. Molnar, Bioorg. Med. Chem., 2002, 10, 1051.

49 R. P. Mason, I. T. Mak, M. W. Trumbore and P. E. Mason, Am. J. Cardiol., 1999, 84, 16.

50 O. Aruoma, C. Smith, R. Cecchini, P. Evans and B. Halliwell, Biochem. Pharmacol., 1991, 42, 735.

51 Y. L. Chen, K. C. Fang, J. Y. Sheu, S. L. Hsu and C. C. Tzeng, J. Med. Chem., 2000, 44, 2374.

52 G. Roma, M. D. Braccio, G. Grossi and M. Chia, Eur. J. Med. Chem., 2000, 35, 1021.

53 M. P. Maguire, K. R. Sheets, K. McVety, A. P. Spada and A. Zilberstein, J. Med. Chem., 1994, 37, 2129.

54 (a) S. J. Ji, Z. Q. Jiang, J. Lu and T. P. Loh, Synlett, 2004, 5, 831; (b) R. Sridhar and P. T. Perumal, Tetrahedron, 2005, 61, 2465; (c) B. X. Du, Y. L. Li, X. S. Wang, M. M. Zhang, D. Q. Shi and S. J. Tu, Chin. J. Org. Chem., 2006, 26, 698.

55 (a) L. Ohberg and J. Westman, Synlett, 2001, 8, 1296; (b) A. Agarwal and P. M. S. Chauhan, Tetrahedron Lett., 2005, 46, 1345; (c) S. Tu, J. Zhang, X. Zhu, Y. Zhang, Q. Wang, J. Xu, B. Jiang, R. Jia, J. Zhang and F. Shi, J. Heterocycl. Chem., 2006, 43, 985.

56 (a) A. P. J. Phillips, J. Am. Chem. Soc., 1949, 71, 4003; (b) G. Anderson and G. J. Berkelhammer, J. Am. Chem. Soc., 1958, 80, 992; (c) H. Singh, D. S. S. Chimni and S. Kumar, Tetrahedron, 1995, 51, 12775.

57 L. M. Wang, J. Sheng, L. Zhang, J. W. Han, Z. Fan, H. Tian and C. T. Qian, Tetrahedron, 2005, 61, 1539.

58 S. Ko and C. F. Yao, Tetrahedron, 2006, 62, 7293.

59 G. Sabitha, G. S. K. Reddy, C. S. Reddy and J. S. Yadav, Tetrahedron Lett., 2003, 44, 4129.

60 B. Das, B. Ravikanth, R. Ramu and B. Vittal Rao, Chem. Pharm. Bull., 2006, 54, 1044.

61 R. Surasani, D. Kalita, A. V. Dhanunjaya Rao, K. Yarbagi and K. B. Chandrasekhar, J. Fluorine Chem., 2012, 135, 91.

62 M. Maheswara, V. Siddaiah, G. L. Damu and C. Venkata Rao, ARKIVOC, 2006, 2, 201.

63 A. Heydari, S. Khaksar, M. Tajbakhsh and H. R. Bijanzadeh, J. Fluorine Chem., 2009, 130, 609.

64 G. Song, B. Wang, X. Wu, Y. Kang and L. Yang, Synth. Commun., 2005, 35, 2875.

65 S. Ko, M. N. V. Sastry, C. Lin and C. F. Yao, Tetrahedron Lett., 2005, 46, 5771.

66 Y. Watanabe, K. Shiota, T. Hoshiko and S. Ozaki, Synthesis, 1983, 9, 761.

67 H. Ahankar, A. Ramazani and S. W. Joo, Res. Chem. Intermed., 2016, 42, 2487.

68 M. M. Heravi, K. Bakhtiri, N. M. Javadi, F. F. Bamoharram, M. Saeedi and H. A. Oskooi, J. Mol. Catal. A: Chem., 2007, 264, 50 .

69 A. Kumar and R. A. Maurya, Tetrahedron, 2007, 63, 1946.

70 A. Kumar and R. A. Maurya, Synlett, 2008, 6, 883.

71 S. T. Fardood, A. Ramazani and S. Moradi, J. Sol-Gel Sci. Technol., 2017, 82, 432. 
72 J. G. Brietenbucher and G. Figliozzi, Tetrahedron Lett., 2000, 41, 4311.

73 J. L. Donelson, A. Gibbs and S. K. De, J. Mol. Catal. A: Chem., 2006, 256, 309.

74 M. Yarie, M. A. Zolfigol, Y. Bayat, A. Asgari, D. A. Alonso and A. Khoshnood, RSC Adv., 2016, 6, 82842.

75 T. Tamoradi, M. Ghadermazi and A. Ghorbani-Choghamarani, Appl. Organomet. Chem., 2018, 32, e3974.

76 C. G. Evans and J. E. Gestwicki, Org. Lett., 2009, 11, 2957.

77 A. Ghorbani-Choghamarani, B. Tahmasbi, P. Moradi and N. Havasi, Appl. Organomet. Chem., 2016, 30, 619.

78 G. J. Chen, J. W. McDonald and W. E. Newton, Inorg. Chem., 1976, 15, 2612.

79 E. Abbaspour-Gilandeh, S. C. Azimi and A. MohammadiBarkchai, RSC Adv., 2014, 4, 54854.

80 E. Abbaspour-Gilandeh, M. Aghaei-Hashjin, A. Yahyazadeh and H. Salemi, RSC Adv., 2016, 6, 55444.

81 E. Abbaspour-Gilandeh, A. Yahyazadeh and M. AghaeiHashjin, RSC Adv., 2018, 8, 40243.

82 A. Khorshidi, K. Tabatabaeian, H. Azizi, M. Aghaei-Hashjin and E. Abbaspour-Gilandeh, RSC Adv., 2017, 7, 17732.

83 A. Yahyazadeh, E. Abbaspour-Gilandeh and M. AghaeiHashjin, Catal. Lett., 2018, 148, 1254.

84 K. Rad-Moghadam, S. C. Azimi and E. Abbaspour-Gilandeh, Tetrahedron Lett., 2013, 54, 4633.

85 A. Maleki, M. Kamalzare and M. Aghaei, J. Nanostruct. Chem., 2015, 5, 95.

86 H. N. Peng, D. G. Zheng and X. M. Peng, Asian J. Chem., 2011, 23, 1833.
87 X. Y. Qin, T. S. Jin, Z. X. Zhou and T. S. H. Li, Asian J. Chem., 2010, 22, 1179.

88 A. R. Moosavi-Zare, M. A. Zolfigol, M. Zarei, A. Zare and J. Afsar, Appl. Catal., A, 2015, 505, 224.

89 M. Nasr-Esfahani, D. Elhamifar, T. Amadeh and B. Karimi, RSC Adv., 2015, 5, 13087.

90 A. Zare, F. Abi, A. R. Moosavi-Zare, M. H. Beyzavi and M. A. Zolfigol, J. Mol. Liq., 2013, 178, 113.

91 M. Nasr-Esfahani, S. J. Hoseini, M. Montazerozohori, R. Mehrabi and H. Nasrabadi, J. Mol. Catal. A: Chem., 2014, 382, 99.

92 S. B. Sapkal, K. F. Shelke, B. B. Shingate and M. Shingare, Tetrahedron Lett., 2009, 50, 1754.

93 C. S. Reddy and M. Raghu, Chin. Chem. Lett., 2008, 19, 775.

94 B. Maleki, R. Tayebee, M. Kermanian and S. Ashrafi, J. Mex. Chem. Soc., 2013, 57, 290.

95 R. S. Amit and S. G. Gavisiddappa, Open Catal. J., 2009, 2, 61.

96 F. Soleimani, M. Salehi and A. Gholizadeh, Iran. J. Polym. Sci. Technol., 2020, 44, 1011.

97 F. K. Behbahani and M. Homafar, Synth. React. Inorg., Met.Org., Nano-Met. Chem., 2012, 42, 291.

98 S. U. Tekale, V. P. Pagore, S. S. Kauthale and R. P. Pawar, Chin. Chem. Lett., 2014, 25, 1149.

99 N. N. Karade, V. H. Budhewar, S. V. Shinde and W. N. Jadhav, Lett. Org. Chem., 2007, 4, 16.

100 R. Ghafouri-Nejad and M. Hajjami, React. Kinet., Mech. Catal., 2020, 129, 371.

101 P. Kulkarni and J. Chil, Chem. Soc., 2014, 59, 2319.

102 D. Aute, A. Kshirsagar, B. Uphade and A. Gadhave, Res. Chem. Intermed., 2020, 46, 3491. 